\title{
Do high stakes and competition undermine fair behaviour? Evidence from Russia ${ }^{\text {th }}$
}

\author{
Ernst Fehr ${ }^{\mathrm{a}, *}$, Elena Tougareva ${ }^{\mathrm{b}, \mathrm{e}}$, Urs Fischbacher $^{\mathrm{c}, \mathrm{d}}$ \\ a University of Zürich, Department of Economics, Blümlisalpstrasse 10, CH-8006 Zürich, Switzerland \\ b Institute of Psychology of the Russian Academy of Sciences, Yaroslavskaya Street, 13, 129366 Moscow, Russia \\ c Department of Economics, University of Konstanz, Universitätsstr. 10, 78457 Konstanz, Germany \\ d Thurgau Institute of Economics, Hauptstrasse 90, 8280 Kreuzlingen, Switzerland \\ e Laboratory of Experimental and Behavioural Economics, National Research University - Higher School of Economics, 26 Shabolovka str, \\ Moscow 119049, Russia
}

A R T I C L E I N F O

Keywords:

Reciprocity

Fairness

Competitive markets

Incentives

Stake size

\begin{abstract}
A B S T R A C T
This paper reports the results of a series of competitive labour market experiments in which subjects have the possibility to reciprocate favours. In the high stake condition subjects earned between two and three times their monthly income during the experiment. In the normal stake condition the stake level was reduced by a factor of ten. We observe that both in the high and the normal stake condition fairness concerns are strong enough to outweigh competitive forces and give rise to non-competitive wages. There is also no evidence that effort behaviour becomes generally more selfish at higher stake levels. Therefore, our results suggest that fairness concerns may play an important role even at relatively high stake levels.
\end{abstract}

\section{Introduction}

During the last decades economists and psychologists have gathered much evidence suggesting that concerns for fairness and reciprocity cannot be ignored in social interactions. This evidence and applications of recently developed theories of social preferences indicate that fairness concerns may help solving problems that have puzzled economists for a long time like, e.g. the persistence of non-competitive wage premia (Agell and Lundborg, 1995; Agell and Bennmarker, 2007; Bewley, 1999; Campbell and Kamlani, 1997), the possibility of involuntary unemployment (Fehr et al., 1993; MacLeod and Malcomson, 1998), the incompleteness of contracts (Fehr et al., 2007), the allocation of property rights (Ellingsen and Johannesson, 2004, 2005; Sonnemans et al., 2001), the conditions for successful collective action (Ostrom, 2000) and the design of contracts (Fehr and Falk, 2002; Englmaier and Wambach, 2010).

Since a considerable part of the evidence for the relevance of fairness concerns comes from questionnaire studies and from laboratory experiments sceptics sometimes dismissed this evidence by claiming that in real life the stakes involved are much higher than in laboratory experiments. Intuitively, it seems compelling to assume that fairness concerns become less relevant when the stakes are high. In addition, it has been frequently pointed out that in competitive environments deviations from

\footnotetext{
is This paper reports the results of experiments conducted in spring 1994 in Moscow, Russia. The paper has benefited from presentations in seminars at Berkeley, Harvard, Pittsburgh, Princeton and Tucson. We thank the participants of these seminars for helpful comments.

* Corresponding author at: Department of Economics, University of Zürich, Blümlisalpstrasse 10, CH-8006 Zürich, Switzerland.

E-mail addresses: ernst.fehr@econ.uzh.ch (E.Fehr), tougareva@yandex.ru (E.Tougareva), urs.fischbacher@uni-konstanz.de, fischbacher@twi-kreuzlingen.ch (U. Fischbacher).
} 
rationality and self-interest are likely to be less important. ${ }^{1}$ Thus, perhaps the interaction between competitive markets and high stakes will render fairness concerns unimportant. Since we believe that these arguments should be taken seriously we conducted a series of competitive labour market experiments in which subjects have the possibility to reciprocate favours.

To study the impact of variations in stake size we implemented a high stake condition, in which the subjects earned on average between two and three times their monthly incomes, and a normal stake condition, in which the subjects' income opportunities were reduced by a factor of ten. To be able to finance these experiments we have conducted them in Moscow (Russia). Both in the high and the normal stake condition subjects participated in a so-called gift exchange experiment. In this experiment wage formation took place in a competitive experimental market and after a labour contract was concluded workers chose the effort level. Fairness concerns can, in principle, play a role in this environment because experimental workers can reciprocate to high wage offers with high effort levels. The experiment is designed such that selfish workers will never make reciprocal effort choices. Yet, if there are sufficiently many fair workers exhibiting reciprocal effort behaviour, paying high, non-competitive, wages may be profitable for the experimental employers.

In contrast to common intuitions and beliefs the ten-fold increase in stake size has little impact on behaviour. We observe no differences in wages at the different stake levels. Both in the high and the normal stake condition experimental employers pay a substantial non-competitive premium. Wages typically are three times higher than the wage that is predicted by the competitive model (based on the assumption of selfish subjects). Moreover, the increase in stake size also has little impact on workers' effort behaviour. On average, workers in both stake conditions exhibit reciprocal effort choices that made it profitable for the employers to pay non-competitive wages. There are small treatment differences in effort levels but the sign of these differences varies with the wage level. At relatively low wages effort is slightly higher in the high stake condition whereas at relatively high wages the reverse holds true. At intermediate wage levels the effort is the same across conditions. We believe that these findings are of interest for labour economists and people who are interested in the potential sources of involuntary unemployment and non-competitive wage premia because the gift exchange experiment captures the spirit of the fairness version of efficiency wage theory (Akerlof, 1982; Akerlof and Yellen, 1990).

To examine potential peculiarities of our Russian subject pool we also conducted two further control experiments in the normal stake condition. In one control treatment we fixed the workers' effort exogenously so that firms had no reason to worry about effort. In this condition the experimental employers did not shy away from paying very unfair wages that are close to the competitive level. ${ }^{2}$ Thus, whereas variations in stake size have no impact on wage formation institutional differences across markets, that is, whether effort is enforced exogenously, lead to radically different wage outcomes. In a second control experiment we observed the behaviour of Austrian subjects in the gift exchange condition. It turns out that wages as well as effort does not differ across the Russian and the Austrian subject pool. This suggests that there is nothing special about our Russian subjects, which strengthens our confidence in the potential generalisability of our high stake results across subject pools.

There are some other papers that examined how a rise in stake size affects the role of fairness concerns in the ultimatum game. $^{3}$ It is well known that the subgame perfect equilibrium in this game involves a strong earnings inequality if both players are selfish and rational. There exists by now a large body of experimental evidence, which contradicts this extreme prediction (e.g. Güth and Tietz, 1990; Roth, 1995; Camerer and Thaler, 1995). Typically, most proposers in the ultimatum game offer between 40 and 50 percent of the available money to the other party and responders reject low offers with high probability. Hoffmann, McCabe and Smith (HMS, 1996) reported the results of ultimatum games with relatively high stakes. HMS varied the stakes from $\$ 10$ to $\$ 100$. Their subjects were students at the University of Arizona. HMS show that the increase in stakes does not affect the proposers' offers. They provide informal evidence that responder rejection rates decreased with stake size. Yet, this claim is difficult to evaluate because they did not provide a statistical analysis of responders' rejection behaviour that controlled for the offers being received by the responders. Cameron (1999) examined the impact of very high stakes. In her experiments subjects could earn three months' income in a one-shot high stake ultimatum game. In the normal stake condition the amount to be divided up between the bargainers is twenty times lower. She reports that the proposers' behaviour is not affected by this large variation in stake size whereas the responders' rejection rates are a bit lower in the high stake condition. Slonim and Roth (1998) observe a similar result although with a different twist. They repeat the ultimatum game ten times with different opponents. They observe that stake size variations do not affect the proposers' behaviour. During the early rounds of the game they also do not find a stake size effect for the responders. However, towards the end of

\footnotetext{
1 "Claims about the irrelevance of models of rational choice and the consequent irrelevance of economics are not uncommon topics of conversation. ... If one looks at experimental markets for evidence, the pessimism is not justified. Market models based on rational choice principles do a pretty good job of capturing the essence of very complicated phenomena" (Plott, 1986, p. 141). Smith (1991, p. 881) writes that markets "reinforce, even induce individual rationality". Such claims are based on the remarkable tendency of competitive experimental markets (with no or little reciprocation opportunities) to converge to the competitive prediction that is derived from assumptions of full rationality and self-interest.

2 It is sometimes argued that "fair" behaviour is driven by the fact that experimenters can observe subjects' actions, i.e. that subjects do not want to appear greedy to the experimenter. However, experimental employers had little problems with appearing greedy in the condition with exogenous effort because they paid very low (unfair) wages. Thus, if subjects are concerned about appearing greedy, this concern seems to be easily overruled by other concerns.

${ }^{3}$ The ultimatum game is a bilateral bargaining game in which two players have to agree how to split a certain amount of money according to the following rules. The proposer makes one proposal of how to split the money. The responder can accept or reject this proposal. If she rejects both players get zero payoff. If she accepts the proposal is implemented.
} 
the experiment the responders exhibit a slightly higher willingness to accept low offers. The strongest effect of stake size in the ultimatum game has been observed by Andersen et al. (2011) who paid their subjects up to roughly one year's salary or the equivalent of roughly 1600 working hours. They find that at their highest stake level responder's rejection rates are very low although they were still sizeable when the stake size was equivalent to 160 working hours. Stake size effects have found to be insignificant in Carpenter et al. (2005) as well as Kocher et al. (2008). Diekmann (2004) summarises the literature on high stakes experiment up to that time and concludes "that altruistic reciprocity remains robust if stakes are high" (page 502). Johansson-Stenman et al. (2005) find lower trust and trustworthiness for higher stakes condition, but also in the high stake condition trust and trustworthiness are remarkably high. Cooperative behaviour under very high stakes has also been studied - and found - in game shows where stakes reach thousands of dollars (List, 2006; Oberholzer-Gee et al., 2010; van den Assem et al., 2012). Recently, Karagözoğlu and Urhan (2013) have compiled a comprehensive overview of stake size effect experiments and come to the conclusion that "the experiments in this field do not lead to clear/common results". ${ }^{4}$

Our study examines the role of fairness concerns in the context of a competitive experimental market. In the absence of opportunities for reciprocation these markets have shown a remarkable tendency to converge towards the competitive prediction (Smith, 1982; Plott, 1989). This allows us to study whether the combination of competition and high stakes does diminish the role of fairness. Yet, as our results show, this is not the case.

Despite the different institutional set-up between our study and the research on stake size variations in the ultimatum game there are some common findings that deserve to be emphasised. ${ }^{5}$ First, all studies report that an increase in stake size does not affect the decisions of the first-movers in the sequentially played game. Second, to the extent to which stake size variations do affect the behaviour of second movers, the effects are remarkably small despite large - ten- or twenty-fold increases in stake size. There is, in particular, no indication that fairness concerns play no longer a role if the stake size is increased up to three months' income.

The remainder of this paper is organised in three sections. In Section 2 the experimental design is presented in some detail. Section 3 examines the data and Section 4 summarises our results.

\section{Experimental design}

Since we are interested in the question whether, and to what extent, competitive markets with high monetary stakes reduce the role of reciprocal fairness our design has to have at least the following three features: (i) It should allow for the possibility of reciprocal fairness, that is, reciprocity should not be ruled out by the design. (ii) The trading institution should be a competitive experimental market and (iii) we need a high and a normal stake condition. The first two of these features are present in the so-called Gift-Exchange Market (Fehr et al., 1993). ${ }^{6}$ Several experiments with Gift Exchange Markets (GEMs) indicate that fairness considerations have a substantial effect on subjects' wage and effort choices and give rise to stable non-competitive outcomes. ${ }^{7}$ The main purpose of this paper is to compare subjects' behaviour in a Gift Exchange Market under normal and high stakes. Since the GEM constitutes the basic element of our experimental design we will next describe its features in more detail. Then we will describe an important control experiment, which we call the complete contracts markets (CCM).

\subsection{The Gift Exchange Market (GEM)}

The GEM is an experimental labour market in which firms act as wage setters while workers have to determine their effort after they have accepted a wage offer. ${ }^{8}$ The GEM-design has two stages: At the first stage wages $w$ are determined in a competitive one-sided oral auction in which each firm can publicly make wage proposals to a group of workers. Workers can accept these offers but they cannot make counteroffers. At the second stage those workers who have accepted a wage offer have to choose an effort level $e \in\{0.1,0.2, \ldots, 1\}$. Both stages together constitute a period and, in general, there are several periods with identical experimental parameters. This stationary repetition allows subjects to become acquainted with the trading institution. In addition, it enables us to study the potential convergence properties of the GEM.

Notice, that in a one-sided oral auction firms cannot make an offer to a specific worker. Any worker can accept the offer and, once it is accepted, a labour contract is concluded. The auction stage has a pre-announced time limit. In our case the limit was three minutes. Within this time limit firms are free to revise their wage offers. The revision of offers has to obey the

\footnotetext{
${ }^{4}$ This echos the conclusion of Camerer and Hogarth (1999) who provide a general review of stake size effects in economic experiments. These authors conclude that the modal effect of higher stakes is to leave mean behaviour unaffected but they reduce the variance of subject's behaviour.

${ }^{5}$ A very important qualification of this generalisation concerns the case of zero stakes. Cameron (1999) also conducted ultimatum games with hypothetical stakes. In these games proposer behaviour was very different compared to games were some real money was at stake. In particular, proposers made much lower offers in the hypothetical stake condition. Thus, our generalisation only applies to situations in which some money is at stake.

${ }^{6}$ Akerlof (1982) interpreted labour contracts as a partial gift exchange. Our choice of labels for the major treatment conditions is based on Akerlof's notion of gift exchange.

7 Charness (2000), Hannan et al. (2002), Fehr et al. (1998) and Brandts and Charness (2004).

8 We present the English translation of our GEM-instructions in the Appendix.
} 
so-called improvement rule, which is common to many different types of auctions. The improvement rule stipulates that, in a given period, any new wage offer has to be higher than the highest offer, which has not yet been accepted by a worker. ${ }^{9}$

An essential feature of the GEM is that the labour contract does not stipulate the effort level. There is an exogenously given level of effort $e_{0}$, which can be enforced by firms. Any $e>e_{0}$ is, however, not enforceable by means of economic incentives. This feature of the GEM is based on a view of the employment relation as a contractually incompletely regulated relationship. The view that labour contracts are rather incomplete and that imperfect enforcement technologies exclude the attainment of certain effort levels is by now widely recognised. ${ }^{10}$

In our GEMs each firm can employ at most one worker and each worker can accept at most one wage offer in a given period. Once those workers who accepted a wage offer have chosen an effort level the period is over and a new one begins. In total, each GEM-session has 10 periods. Firms' payoff function in experimental currency (Guilders) is given by

$$
\Pi=(v-w) e,
$$

where $v$ is an exogenously given redemption value. Workers' payoff function in experimental money (Guilders) is given by

$$
U=w-c(e)-c_{0}
$$

$c(e)$ represents the effort cost function and obeys the conditions $c\left(e_{0}\right)=0$ and $c^{\prime}>0 . c_{0}$ denotes an exogenously given level of fixed costs of working. In case that a subject does not trade his or her payoff is zero.

The payoffs in experimental money are transformed into real money payoffs at the end of the experiment. The exchange rate between experimental money and real money is the same for both workers and firms and it is common knowledge. To exclude the possibility of losses wage offers above $v$ and below $c_{o}$ are not allowed. The choice of payoff function (1) is also guided by the attempt to avoid losses. It is by now well known that behaviour may be affected by loss aversion. ${ }^{11}$ Since we want to rule out that the impact of reciprocal fairness is "polluted" by loss aversion phenomena we implemented payoff function (1) instead of the more familiar function $\Pi=v e-w$. As will be shown below, under the usual assumption of rational money maximising agents, our choice of the payoff function would neither qualitatively nor quantitatively affect the behaviour of experimental subjects.

\subsection{Treatment conditions}

The main purpose of this paper is to compare the behaviour of our Russian subjects under high and normal stakes GEMs. However, to rule out that potential peculiarities of Russian subjects are responsible for our results we perform two checks. First, we compare the behaviour of the Russian subjects with the behaviour of Austrian subjects under conditions of a normal stake GEM. More specifically, we compare the results of our normal stake GEM experiments with the GEMexperiments conducted by Fehr et al. (1998). ${ }^{12}$ Second, we run a so-called Complete Contracts Market (CCM) experiment with the Russian subjects in the normal stake condition. A CCM is similar to a GEM except that there are no possibilities for reciprocation because the effort level is exogenously fixed. Therefore, all phenomena in the GEM, which are due to the possibility of reciprocal effort choices should not be observed in the CCM. In Fehr et al. (1998) it has been shown that, in the case of an exogenously fixed effort level, non-competitive wages tend to vanish over time. It would thus be reassuring if the same happens among the Russian subjects. Our CCM also lasts for ten periods and wages are determined in a one-sided oral auction. As in the GEM a worker can accept at most one offer per period and a firm can employ at most one worker.

Contrary to the GEM there is no effort stage in the CCM. $e$ is set exogenously equal to one and no effort costs are subtracted from a worker's wage. ${ }^{13}$ In the CCM the payoff in terms of experimental money from a labour contract are, therefore, given by

$$
\begin{aligned}
& \Pi=v-w \\
& U=w-c_{0}
\end{aligned}
$$

\footnotetext{
${ }^{9}$ Notice, that this rule does not rule out underbidding. Assume that the best wage offer is, for example, 60 while the second best offer is 50 . A firm who wants to bid only 51, has to wait until 60 is accepted. Then it can offer 51.

10 In the textbook of Milgrom and Roberts (1992) we find, for example, the following paragraph (p. 329): “The employment contract is typically quite imprecise. The employees agree that - within limits that are rarely completely described and only partly understood - they will use their minds and muscles to undertake the tasks that the employer directs them to do, perhaps using the methods that the employer specifies. The employer agrees to pay the employees. The range of actions that might be requested or required is unclear. Future compensation and even the criteria used to determine future pay and promotions are unspecified. The mechanism to be used in case of dispute is not stated, nor are the penalties for most possible violations of the contract."

11 For a summary see Tversky and Kahneman (1991).

12 For the purpose of this comparison our Russian instructions constitute a translation of the instructions used by Fehr et al. (1998). We applied the method of back translation. First, the instructions were translated from German into Russian. Then, a different person translated them back into German. If the back translation indicated a deviation from the original instructions the two translators together with a third translator and an experimenter had to clarify the issue. The experiments in Russia and Austria are based on the same parameters and information conditions. To control for experimenter effects both E. Tougareva and E. Fehr were present during the experiments in Austria and in Russia.

13 In this respect the payoff is not the same as the payoff in the GEM with the highest possible effort.
} 
Table 1

Effort cost schedule.

\begin{tabular}{|c|c|c|c|c|c|c|c|c|c|c|}
\hline Effort & 0.1 & 0.2 & 0.3 & 0.4 & 0.5 & 0.6 & 0.7 & 0.8 & 0.9 & 1 \\
\hline Cost & 0 & 1 & 2 & 4 & 6 & 8 & 10 & 12 & 15 & 18 \\
\hline
\end{tabular}

All other aspects of the CCM are identical to the GEM.

\subsection{Information conditions}

In the GEM as well as in the CCM the parameters $v, c_{0}, c(e)$, the number of workers $L$, the number of firms $N$, the fact that there were ten periods and the exchange rate between experimental money and real money are common knowledge. At the beginning of each session a random mechanism determines whether a subject is a firm or a worker. Before the start of a ten-period session a trial period is conducted in which no money is at stake. Before this trial period subjects have to solve several exercises in which they have to compute their own money payoffs as well as the money payoffs of their trading partner from hypothetical trades.

Neither in the GEM nor in the CCM the subjects know the identity of their trading partner. To ensure this anonymity condition firms and workers are located in different rooms and the communication between these rooms takes place by means of a telephone. Because of the anonymity of trades no firm can signal workers that it is a high or a low wage firm. Nor can workers develop a reputation as high or low effort workers. It is also not possible that subjects punish or reward past actions of their current trading partners because they do not know the identity or the past actions of their trading partners.

All wage offers are public information. They are written on a blackboard in both rooms. As soon as a particular wage offer is accepted it is deleted from the blackboard. In addition, all other offers of the trading firm are also deleted because they are no longer available. Effort levels in the GEM are only known to the firm-worker pair who participates in a trade. In the GEM a worker does not know the effort levels of other workers. The reason for this is that we want to rule out group-pressure effects. These information conditions ensure that subjects can compute their own payoffs and the payoffs of their trading partners.

\subsection{Parameters and competitive predictions}

In all GEMs and CCMs we set $v=120$ and $c_{0}=20$. The effort cost schedule in the GEMs is given by Table 1 .

In the GEM as well as in the CCM there are always 9 workers and 6 firms. Due to this excess supply of workers the competitive wage for the CCM is given by $w^{c}=c_{0}=20$, in case that subjects exhibit exclusively selfish preferences. The competitive wage for the GEM is the same: For any given wage offer a rational money maximising worker will always choose the lowest effort because any other level would lower U. Since at $e=0.1$ workers' reservation wages are given by $c_{0}=20$ wages in the GEM and the CCM should not differ according to the competitive prediction.

\subsection{Testing for the effects of high monetary stakes}

To study the effects of high monetary stakes we have conducted eight GEMs in Moscow. In four of these GEMs, denoted by $s 1-s 4$, the exchange rate between experimental Guilders and real money generated an income, which was comparable to the income earned by Austrian subjects in the GEM-experiments of Fehr et al. (1998). In the other four GEMs, which we denote by S1-S4, the exchange rate was increased by a factor of ten, i.e. subjects' income opportunities in the "high stake" GEMs are ten times higher.

We paid subjects in US Dollars. In the normal stake-GEM they received 2 US-cents per unit of experimental currency (Guilders) while in the high stake-GEM they received 20 cents. To increase the awareness of the exchange rate between Guilders and Dollars the exchange rate was noted at the top of each decision sheet. In our GEMs the maximum gains per trade were 100 Guilders. Therefore, the maximum gains in terms of US-Dollars amount to $\$ 20$. The median subject in our subject pool had a monetary income per month of slightly less than $\$ 17 .{ }^{14} 64$ percent had a monetary monthly income of less than $\$ 20$. On average, subjects earned between $\$ 40$ and $\$ 50$ in a high stake GEM-session. It is, thus fair to say that about two thirds of our subjects earned between 2 and 3 times their monetary monthly incomes in a two hour GEM-session with high stakes. The experiments were conducted between March and May 1994. Four sessions (s1, s2, S1, S2) were organised in March, the other four (s3, s4, S3, S4) in May 1994.

The monthly(!) Roubel inflation during the first half of 1994 varied between 9 and 22 percent. As a consequence, the Dollar became a major store of value and a significant part of everyday transactions took place in Dollars. Due to the high

\footnotetext{
14 We elicited information about subjects' income by a questionnaire before the starts of the first trading round. Subjects were asked to write down what they earn on average per month in each of the following income categories: (i) monthly student grant, (ii) salary in case of a permanent job, (iii) average income of occasional jobs, (iv) average income they get from parents or relatives, (v) income from other sources. They were asked to reveal their incomes truthfully. In order to give them an incentive for truthful revelation the questionnaire did not contain their names or their subject numbers. They filled out the questionnaire privately, put it into an unmarked envelope and threw it into a "voting" box.
} 


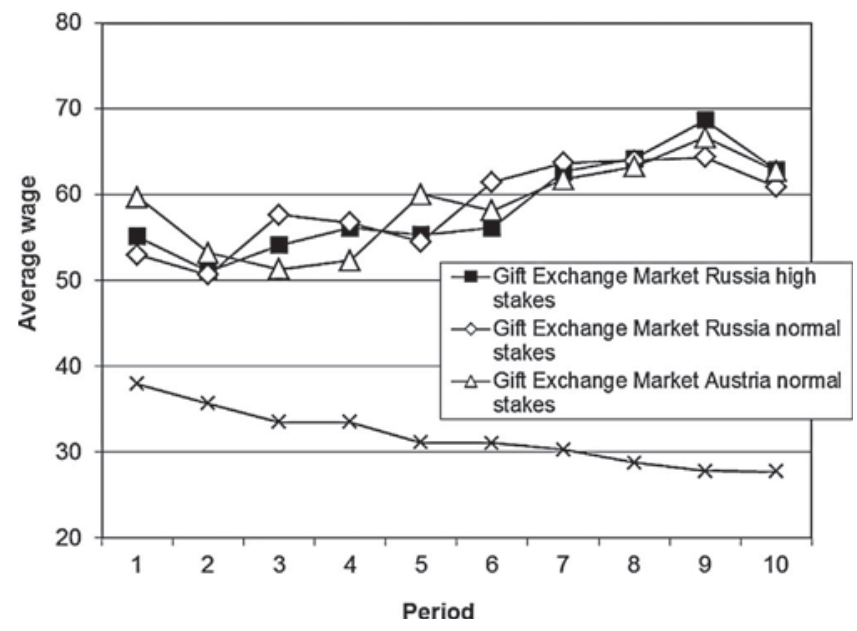

Fig. 1. The impact of stake size on average wages.

Roubel inflation households tended to convert the money, which they did not need for immediate consumption purposes, as soon as possible into Dollars. ${ }^{15}$ Thus, knowledge of the Dollar-Roubel exchange rate was vital in these circumstances. Since virtually everybody could be expected to know the Roubel-Dollar exchange rate under these circumstances we considered the dangers of money illusion to be negligible if we paid subjects in Dollars. ${ }^{16}$ Taken together, it is reasonable to assume that subjects in the high stake GEMs considered the potentially achievable gains per trade as a very large amount of money. ${ }^{17}$

The comparison of outcomes between s1-s4 on the one hand and S1-S4 on the other hand allows an investigation of the effects of a rise in stakes. In case that we observe in both treatments a significant and similar amount of reciprocally fair behaviour the question arises whether this is due to a general inclination of Russian subjects to be fair or whether it is due to the possibility of reciprocal effort choices in the GEM. To discriminate between these hypotheses we organised four CCMs with normal stakes. The exchange rate between Guilders and real money in these CCMs was 1 Guilder $=4 / 3$ Cents. This exchange rate provides subjects in the CCMs on average with the same overall income as in the normal stake GEMs. The same subjects who participated first in the normal stake GEMs were present in the CCMs, that is, the normal stake GEM and the CCM were part of the same overall session. The GEM always took place first and subjects did not know that after the GEM a CCM-experiment will take place. Moreover, subjects in the CCMs were in the same role as in the normal-stake-GEMs.

\section{Results}

In total 120 subjects participated in our Russian sessions. 60 subjects were present in the GEMs and CCMs of the normal stake sessions (s1-s4) and 60 subjects participated in our high stake -GEMs S1-S4. All our subjects were first and second year undergraduates from a college, which provides mainly education for engineers. On average, a GEM lasted 1.5-2 hours while a CCM lasted approximately 45 minutes. The number of potential trades in each GEM as well as in each CCM is 60 . Therefore, the total number of GEM-trades (CCM-trades) is 480 (240). The actual number of trades in the GEMs was 479 while in the CCMs it was 238. Our first main result deals with wage differences across the different treatments.

Result 1. The wage is not affected by stake size. In contrast, the possibility of reciprocal effort choices in the gift exchange market has a large impact on wage levels.

A first indication for Result 1 is provided in Fig. 1, which shows the time pattern of average wages across treatment conditions for the Russian subjects. The figure shows that in all periods the average wage in the high and normal stake GEMs is very similar. This contrasts sharply with the level and the time pattern of wages in the CCMs. Already in period 1 there is a large difference in wages across GEMs and CCMs. In addition, whereas wages in the CCMs slowly but steadily converge towards the competitive level of 20, wages in the GEMs even increase over time. Overall, in the CCMs 86 percent of all wages are below 40 whereas in the GEMs roughly 75 percent of all wages are above 50. Fig. 1 makes it already transparent that

\footnotetext{
15 These exchange needs caused the existence of a large number of exchange offices. Banks made many advertisements for Dollar accounts and TV-News announced the exchange rate several times a day.

${ }^{16}$ We controlled for this kind of money illusion by asking subjects to compute the Roubel value of their dollar earnings at the end of the experiment. Many of them asked us which exchange rate they should take, those for buying Roubels or those for selling Roubels. There was no subject, which failed to do this exercise correctly.

17 This view is further corroborated by a comparison of the monthly incomes of our experimental assistants, who where 30 years old adults with regular jobs at the Russian Academy of Sciences, with the experimental incomes of our subjects. Whereas subjects earned between $\$ 40$ and $\$ 50$ in a two-hour session our experimental assistants had a monthly income of roughly $\$ 30$ and even this low income had not been paid to them for several previous months.
} 


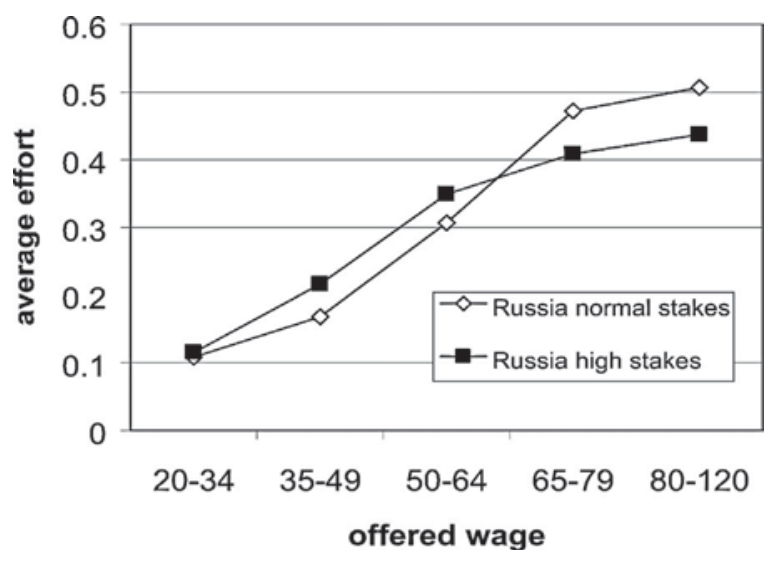

Fig. 2. The impact of stake size on effort choices.

the institutional differences between the GEM and the CCM are much more important for wage formation than the stake differences across the GEM-treatments.

Result 1 is also supported by formal statistical tests. A non-parametric Mann Whitney test with the average wage per session as the unit of observation indicates that the null hypothesis of equal wages across stake sizes cannot be rejected for the GEMs $(p=0.56)$. A regression of individual wages in the GEMs on a constant and a high stake dummy yields the same result. The high stake dummy has a coefficient of -.07 and a $t$-statistic of $-.01(p=.991) .{ }^{18}$ Thus, as suggested by Fig. 1 , stake size does not affect wage levels in the GEMs. In contrast to this, the wage difference across GEMs and CCMs is significant. The null hypothesis of equal wages across high stake GEMs and CCMs can be rejected (Mann Whitney test, average wage per session as unit of observation, $p=0.021)$.

Previous Gift Exchange experiments (e.g. Fehr et al., 1998) have shown that the workers' reciprocal effort behaviour is the driving force behind non-competitive wages because workers' reciprocity makes it profitable for the firms to pay noncompetitive wage premia. Therefore, the fact that wages are similar across stake conditions suggests that effort behaviour is also similar. Our next result sheds more light on this issue.

Result 2. At low wages effort is higher in the high stake condition whereas at high wages effort is higher in the normal stake condition. The differences across stake conditions are, however, small and, often, insignificant.

Support for Result 2 comes from Fig. 2 and Table 2. Fig. 2 shows how the average effort varies across different wage intervals. The figure indicates that in the wage intervals [35,49] and $[50,64]$ effort is slightly higher in the high stake condition whereas for wages above 64 the reverse holds true. For wages at about 60 effort levels are the same across conditions. For each of the wage intervals in Fig. 2 we have conducted Mann Whitney tests of the null hypothesis of equal effort levels across stake conditions. It turns out that only in the interval $[35,49]$ effort levels are significantly different $(p=.04)$.

To further explore differences in effort choices we ran several OLS and ordered probit regressions (see Table 2). In all regressions displayed in Table 2 we computed robust standard errors that allow for dependent within-session observations. This procedure is necessary because the observations within a given session cannot be assumed to be uncorrelated. The OLS regression 1 in Table 2 relates individual effort on a constant, the worker's wage, a high-stake dummy and an interaction term between the wage and the high-stake dummy. The coefficient on wages is highly significant and positive indicating a positive effort-wage relation in the normal stake condition. The high-stake dummy is also significantly positive suggesting that at lower wage levels subjects provide more effort in the high stake condition. The interaction term between wages and high stakes is significantly negative. The results of regression 1 imply that for wages sufficiently above 60 the effort tends to be higher in the normal stake condition.

To check the robustness of this conclusion we also ran ordered probit regressions. The probit regression takes into account that the effort could not be chosen continuously and cannot be lower than 0.1 and higher than $1 .{ }^{19}$ Regression 2 shows that the qualitative results described above remain unchanged. The inclusion of a quadratic wage term in regressions 3 and 4 also does not change our conclusions. The quadratic term is negative and, in equation 4 , significant indicating that the effort-wage relations is concave. Yet, the results of regressions 3 and 4 also imply that at lower wages effort is higher in the high-stake condition whereas at wages above 60 effort is higher in the normal stake condition.

In their paper on high stake ultimatum games Slonim and Roth (1998) find an interaction effect between experience and the stake level. During the final periods of the "repeated" ultimatum game subjects' propensity to reject low offers is slightly

\footnotetext{
18 This t-statistic is based on robust standard errors taking into account the possibility that within-session wage observations may be dependent. Only across-session wage observations are treated as independent variables.

${ }^{19}$ We also ran interval regressions. They yield the same qualitative results as the OLS and the ordered probit regressions.
} 
Table 2

The impact of stake size on effort levels.

\begin{tabular}{|c|c|c|c|c|c|c|}
\hline & $\begin{array}{l}(1) \\
\text { OLS }\end{array}$ & $\begin{array}{l}(2) \\
\text { Ordered Probit }\end{array}$ & $\begin{array}{l}\text { (3) } \\
\text { OLS }\end{array}$ & $\begin{array}{l}(4) \\
\text { Ordered Probit }\end{array}$ & $\begin{array}{l}\text { (5) } \\
\text { OLS }\end{array}$ & $\begin{array}{l}(6) \\
\text { Ordered Probit }\end{array}$ \\
\hline Constant & $\begin{array}{l}-0.211^{* * *} \\
(0.059)\end{array}$ & & $\begin{array}{l}-0.338^{*} \\
(0.157)\end{array}$ & & $\begin{array}{l}-0.195^{* * *} \\
(0.052)\end{array}$ & \\
\hline Wage & $0.009^{* * * *}$ & $\begin{array}{l}0.051^{* * *} \\
(0.003)\end{array}$ & $\begin{array}{l}0.014^{* *} \\
(0.005)\end{array}$ & $\begin{array}{l}0.124^{* * *} \\
(0.032)\end{array}$ & $\begin{array}{l}0.010^{* * 3} \\
(0.001)\end{array}$ & $\begin{array}{l}0.056^{* * *} \\
(0.003)\end{array}$ \\
\hline $\begin{array}{l}\text { High stake } \\
\text { Dummy }\end{array}$ & $\begin{array}{l}0.259^{* * *} \\
(0.073)\end{array}$ & $\begin{array}{l}1.573^{* * *} \\
(0.295)\end{array}$ & $\begin{array}{l}0.218^{* *} \\
(0.081)\end{array}$ & $\begin{array}{l}1.096^{* * *} \\
(0.240)\end{array}$ & $\begin{array}{l}0.232^{* * *} \\
(0.061)\end{array}$ & $\begin{array}{l}1.470^{* * *} \\
(0.248)\end{array}$ \\
\hline High stake $\times$ wage & $\begin{array}{l}-0.005^{* *} \\
(0.001)\end{array}$ & $\begin{array}{l}-0.027^{* * *} \\
(0.005)\end{array}$ & $\begin{array}{l}-0.004 \\
(0.002)\end{array}$ & $\begin{array}{l}-0.017^{* * *} \\
(0.005)\end{array}$ & $\begin{array}{l}-0.006^{* *} \\
(0.002)\end{array}$ & $\begin{array}{l}-0.033^{* * *} \\
(0.006)\end{array}$ \\
\hline Wage $^{2}$ & & & $\begin{array}{l}-0.000 \\
(0.000)\end{array}$ & $\begin{array}{l}-0.001^{* *} \\
(0.000)\end{array}$ & & \\
\hline Period & & & & & $\begin{array}{l}-0.012^{*} \\
(0.005)\end{array}$ & $\begin{array}{l}-0.067^{* * *} \\
(0.020)\end{array}$ \\
\hline High stake $\times$ period & & & & & $\begin{array}{l}0.015 \\
(0.009)\end{array}$ & $\begin{array}{l}0.083^{* *} \\
(0.041)\end{array}$ \\
\hline Last period & & & & & 0.014 & 0.101 \\
\hline Dummy & & & & & $(0.028)$ & $(0.120)$ \\
\hline High stake $\times$ last period & & & & & $\begin{array}{l}0.014 \\
(0.039)\end{array}$ & $\begin{array}{l}0.026 \\
(0.180)\end{array}$ \\
\hline (pseudo) $R^{2}$ & 0.207 & 0.0556 & 0.211 & 0.0626 & 0.219 & 0.0594 \\
\hline$N$ & 479 & 479 & 479 & 479 & 479 & 479 \\
\hline \# Clusters & 8 & 8 & 8 & 8 & 8 & 8 \\
\hline
\end{tabular}

Note: The table is based on data from the normal stake and high stake Russian Gift Exchange Experiments. Robust standard errors, clustering on sessions, are in parentheses.

*** Significance at the 1 percent level.

** Significance at the 5 percent level.

Significance at the 10 percent level.

lower in the high stake condition. ${ }^{20}$ This raises the question whether subjects are less willing to provide non-minimal effort levels in the final periods of our GEMs. To examine this question we have added a period variable and a last period dummy to regressions 1 and 2. In addition, we interacted these variables with the high stake dummy. The results of these regressions are displayed in equations 5 and 6 of Table 2. The table shows that the period coefficient is significantly negative. However, the interaction with the high stake dummy is positive and larger than the period coefficient. In the ordered probit regression it is even significantly positive. Thus subjects behave more selfishly over the course of the experiment, but only in the low stake treatment. Apart from the time trend, there is no significant end game effect, which is reflected in the insignificant coefficient of the last period dummy. Thus, the effect of high stakes is the opposite of what one might expect in view of the results in Slonim and Roth (1998) because they eliminates the negative time trend. In comparison with the normal stake condition effort is higher in the high stakes condition towards the end of the experiment.

Result 1 and Result 2 suggest that high stakes cause no differences in wage setting and only small differences in effort behaviour. This raises the question to what extent our results can be generalised beyond the Russian context. A fully convincing answer to this question can of course only be given if one conducts the same experiments outside of Russia. However, if it were possible to show that - in the normal stake condition - Russian subjects behave similar to Non-Russian subjects there would be little reason to believe that in the high stake condition cross-national differences would show up. Therefore, we next turn to this question.

Result 3. There is no difference in wages and effort levels across the Austrian and Russian gift exchange markets with normal stakes.

Support for Result 3 is provided in Figs. 1 and 3 and in Table 3. Fig. 1 shows that the level and the time pattern of wages are very similar across Austrian and Russian GEMs. Sometimes wages in Austria are a bit higher, sometimes they are higher in Russia. Towards the end of the experiment wages are, in fact, very close to each other. This picture is also supported by statistical test. A Mann Whitney test, with session averages as the unit of observation, indicates no significant differences $(p=1.0)$ and if we regress individual wages on a constant and a dummy for Austria, the coefficient of the dummy variable is small (0.07) and highly insignificant $(p=0.984)$.

With regard to effort behaviour a similar picture emerges. Fig. 3 shows that at some wage intervals effort is slightly higher in Austria but these differences are not even close to significant. In Table 3 we report our regression results for the normal stake GEM-sessions in Austria and Russia. Whereas the constant and the wage slope coefficient are highly significant

\footnotetext{
20 In Slonim and Roth subjects meet a new partner in every period. Thus, each ultimatum game is one-shot but they can still study the role of experience because subjects meet 10 different opponents.
} 


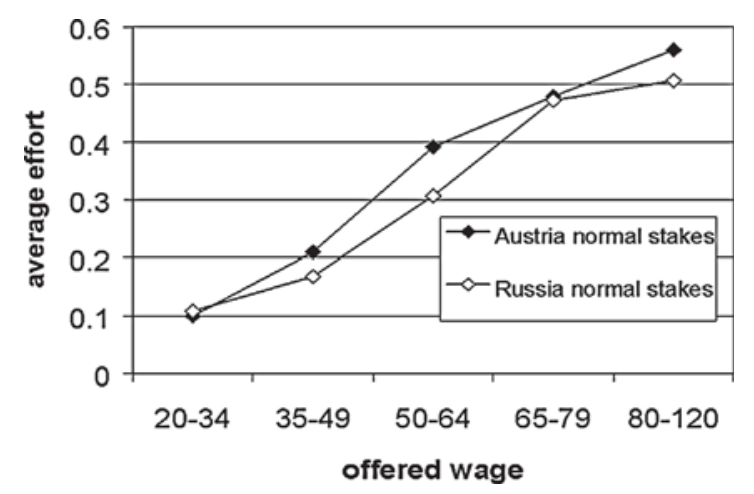

Fig. 3. Effort choices in Russian and Austrian normal stake sessions.

Table 3

Effort Behaviour in gift exchange markets with normal stakes in Austria and Russia.

\begin{tabular}{lll}
\hline & $(1)$ & $(2)$ \\
& OLS & Ordered Probit \\
\hline Constant & $-0.211^{* * *}$ & \\
Wage & $(0.059)$ & $0.052^{* * *}$ \\
& $0.009^{* * *}$ & $(0.005)$ \\
Austria dummy & $(0.001)$ & 0.626 \\
Austria $\times$ wage & 0.082 & $(0.559)$ \\
& $(0.095)$ & -0.006 \\
$R^{2}$ & -0.001 & $(0.009)$ \\
$N$ & $(0.002)$ & 0.0731 \\
\# Clusters & 0.249 & 500 \\
\hline
\end{tabular}

Note: The table is based on data from the normal stake and high stake Russian Gift Exchange Experiments. Robust standard errors, clustering on sessions, are in parentheses.

**** Significance at the 1 percent level.

* Significance at the 5 percent level.

Significance at the 10 percent level.

the dummy variable for Austria as well as the interaction between the Austria-dummy and the wage are insignificant exhibiting in all cases a standard error that exceeds the value of the coefficient. Thus, taken together these data suggest that with regard to wages and effort there are no significant cross-national differences in the normal stake GEMs.

\section{Summary}

Common intuitions about the relevance of fairness motives seem to suggest that these motives are less important in competitive environments and in environments where large amounts of money are at stake. We have examined this question by conducting gift exchange experiments in a competitive environment under normal and under high stakes. In the high stake condition the stake level was ten times higher than in the normal stake condition enabling subjects to earn between two and three times their monthly incomes in a two hour experiment. Despite this strong increase in the stake level wages in the gift exchange condition are indistinguishable across stake levels - exhibiting a substantial non-competitive wage premium. In sharp contrast to the high non-competitive wages in the gift exchange condition wages converge close to competitive levels when workers' effort is exogenously fixed. This indicates that the institutional differences between the gift exchange market and the complete contracts market are much more important than differences in stake levels.

In the domain of effort behaviour stake levels seem to have a small impact. For wages up to about 60, effort tends to be slightly higher in the high stake condition while for wages above 60 they are somewhat lower. These differences are however very small and, apparently, did not affect wage setting behaviour. Moreover, the combination of high stakes and experience does also not induce experimental workers' to make more greedy effort choices. If anything, effort is higher in the high stake condition towards the end of the experiment. One might wonder whether our results depend on the specific parameters of the game. Of course, this cannot be excluded. Nevertheless, Dittrich and Ziegelmeyer (2006) studied different variants of the gift exchange game. They find that wages strongly depend on the parameters while the effort-wage relation is robust.

Our results and the results of Cameron (1999) suggest that up to roughly three months' income the strength of fairness motives exhibits little response to stake levels. Thus, doubts about the external validity of fair behaviour in laboratory experiments that are based on the argument that the stake level in the experiment is not sufficiently high are not supported 
by the data - at least up to stake levels of three months income. We can, of course, not rule out that for stake levels beyond three months' income stake size has a bigger behavioural impact. However, if one judges the relevance of our results one should ask oneself, how many daily choices involve more than three months' income. We are quite confident that for most people most of their choices involve a substantially lower amount of resources. If one accepts this claim there is little basis for questioning the relevance of fairness motives for reasons of insufficient stake size for the bulk of people's choices.

\section{Appendix A. Supplementary data}

Supplementary data associated with this article can be found, in the online version, at http://dx.doi.org/10.1016/j.jebo. 2013.09.005.

\section{References}

Agell, J., Lundborg, P., 1995. Theories of pay and unemployment: survey evidence from swedish manufacturing firms. Scandinavian Journal of Economics 97, 295-308.

Agell, D J., Bennmarker, H., 2007. Wage incentives and wage rigidity: a representative view from within”. Labour Economics 14, 347-369.

Akerlof, G.A., 1982. Labor contracts as partial gift exchange. Quarterly Journal of Economics 97, 543-569.

Akerlof, G.A., Yellen, J.L., 1990. The fair wage-effort hypothesis and unemployment. Quarterly Journal of Economics 105, 255-283.

Andersen, S., Ertac, S., Gneezy, U., Hoffman, M., List, J., 2011. Stakes matter in ultimatum games. American Economic Review 101, 3427-3439.

Bewley, T., 1999. Why Wages Don't Fall During a Recession. Harvard University Press, Harvard.

Brandts, J., Charness, G., 2004. Do labour market conditions affect gift exchange? Some experimental evidence. Economic Journal 114, 684-708.

Camerer D C., Thaler, R., 1995. Ultimatums, dictators, and manners. Journal of Economic Perspectives 9, 209-219.

Camerer, C., Hogarth, R., 1999. The effects of financial incentives in experiments: a review and capital-labor-production framework. Journal of Risk and Uncertainty 19, 7-42.

Cameron, L.A., 1999. Raising the stakes in the ultimatum game: experimental evidence from Indonesia. Economic Inquiry 37, 47-59.

Campbell, C.M., Kamlani, K.S., 1997. The reasons for wage rigidity: evidence from a survey of firms. Quarterly Journal of Economics 112, 759-789.

Carpenter, J., Verhoogen, E., Burks, S., 2005. The effect of stakes in distribution experiments. Economics Letters 86, $393-398$.

Charness, G., 2000. Responsibility and effort in an experimental labor market. Journal of Economic Behavior and Organization 42, 375-384.

Diekmann, A., 2004. The power of reciprocity: fairness, reciprocity, and stakes in variants of the dictator game. Journal of Conflict Resolution 48, 487-505.

Dittrich, D.A.V., Ziegelmeyer, A., 2006. Laboratory Bilateral Gift Exchange: The Impact of Loss Aversion, Papers on Strategic Interaction 2005-34. Max Planck Institute of Economics, Strategic Interaction Group.

Ellingsen, T., Johannesson, M., 2004. Is there a hold-up problem? Scandinavian Journal of Economics 106, 475-494.

Ellingsen, T., Johannesson, M., 2005. Sunk costs and fairness in incomplete information bargaining. Games and Economic Behavior 50, 155-177.

Englmaier, F., Wambach, A., 2010. Optimal incentive contracts under inequity aversion. Games and Economic Behavior 69, 312-328.

Fehr, E., Kirchsteiger, G., Riedl, A., 1993. Does fairness prevent market clearing - an experimental investigation. Quarterly Journal of Economics 108, 437-459.

Fehr, E., Kirchler, E., Weichbold, A., Gächter, S., 1998. When social norms overpower competition: Gift exchange in experimental labor markets. Journal of Labor Economics 16, 324-351.

Fehr, E., Klein, A., Schmidt, K.M., 2007. Fairness and contract design. Econometrica 75, 121-154.

Fehr, E., Falk, A., 2002. Psychological foundations of incentives. European Economic Review 46, 687-724.

Güth, W., Tietz, R., 1990. Ultimatum bargaining behaviour - a survey and comparison of experimental results. Journal of Economic Psychology $11,417-449$. Hannan, R.L., Kagel, J.H., Moser, D.V., 2002. Partial gift exchange in an experimental labor market: impact of subject population differences, productivity differences, and effort requests on behavior. Journal of Labor Economics 20, 923-951.

Hoffman, E., McCabe, K., Smith, V., 1996. On expectations and monetary stakes in ultimatum games. International Journal of Game Theory $25,289-301$.

Johansson-Stenman, O., Mahmud, M., Martinsson, P., 2005. Does stake size matter in trust games? Economics Letters 88, $365-369$.

Karagözoğlu, E., Urhan, Ü.B. (2013). The effect of stake size in experimental bargaining and distribution games, mimeo Bilkent University.

Kocher, M.G., Martinsson, P., Visser, M., 2008. Does stake size matter for cooperation and punishment? Economics Letters 99, 508-511.

List, J.A., 2006. Friend or Foe? A natural experiment of the prisoner's dilemma. Review of Economics and Statistics 88, 463-471.

MacLeod, W.B., Malcomson, J.M., 1998. Motivation and markets. American Economic Review 88, 388-411.

Milgrom, P., Roberts, J., 1992. Economics, Organization and Management. Prentice Hall, New Jersey.

Oberholzer-Gee, Waldfogel, J., White, M.W., 2010. Friend or foe? Cooperation and learning in high-stakes games. Review of Economics and Statistics 92, 179-187.

Ostrom, E., 2000. Collective action and the evolution of social norms. Journal of Economic Perspectives 14, 137-158.

Plott, C.R., 1986. Rational choice in experimental markets. In: Hogarth, R.M., Reder, M.W. (Eds.), Rational Choice - The Contrast Between Economics and Psychology. University of Chicago Press, Chicago, pp. 117-144.

Plott, C.R., 1989. An updated review of industrial organisation: applications of experimental methods. In: Schmalensee, R., Willig, R. (Eds.), Handbook of Industrial Organisation, vol. 2. North Holland, pp. 1109-1176.

Roth, A.E., 1995. Bargaining experiments. In: Kagel, J.A., Roth, A.E. (Eds.), Handbook of Experimental Economics. Princeton University Press, Princeton.

Slonim, R., Roth, A.E., 1998. Financial incentives and learning in ultimatum and market games: an experiment in the slovak republic. Econometrica 66, 569-596.

Smith, V.L., 1982. Microeconomic systems as an experimental science. American Economic Review 72, 923-955.

Smith, V.L., 1991. Rational choice: the contrast between economics and psychology. Journal of Political Economy 99, 877-897.

Sonnemans, J., Oosterbeek, H., Sloof, R., 2001. On the relation between asset ownership and specific investments. Economic Journal 111, $791-820$.

Tversky, A., Kahneman, D., 1991. Loss aversion in riskless choice - a reference-dependent model. Quarterly Journal of Economics 106, $1039-1061$.

van den Assem, M.J., van Dolder, D., Thaler, R.H., 2012. Split or steal? Cooperative behavior when the stakes are large. Management Science 58, 2-20. 